\title{
Fixed point theorem for weakly Chatterjea-type cyclic contractions
}

\author{
Sumit Chandok ${ }^{1}$ and Mihai Postolache ${ }^{2^{*}}$
}

\section{"Correspondence:}

mihai@mathem.pub.ro

${ }^{2}$ Faculty of Applied Sciences,

University Politehnica of Bucharest,

313 Splaiul Independenţei,

Bucharest, 060042, Romania

Full list of author information is

available at the end of the article

\begin{abstract}
In this article, we introduce the notion of a Chatterjea-type cyclic weakly contraction and derive the existence of a fixed point for such mappings in the setup of complete metric spaces. Our result extends and improves some fixed point theorems in the literature. Example is given to support the usability of the result.

MSC: $41 \mathrm{~A} 50 ; 47 \mathrm{H} 10 ; 54 \mathrm{H} 25$
\end{abstract}

Keywords: fixed point; cyclic contraction mapping

\section{Introduction and preliminaries}

It is well known that the fixed point theorem of Banach, for contraction mappings, is one of the pivotal results in analysis. It has been used in many different fields of mathematics but suffers from one major drawback. More accurately, in order to use the contractive condition, a self-mapping $T$ must be Lipschitz continuous, with the Lipschitz constant $L<1$. In particular, $T$ must be continuous at all points of its domain.

A natural question arises:

Could we find contractive conditions which will imply the existence of a fixed point in a complete metric space but will not imply continuity?

Kannan [1,2] proved the following result giving an affirmative answer to the above question.

Theorem 1.1 If $(X, d)$ is a complete metric space and the mapping $T: X \rightarrow X$ satisfies

$$
d(T x, T y) \leq k[d(x, T x)+d(y, T y)]
$$

where $0<k<\frac{1}{2}$ and $x, y \in X$, then $T$ has a unique fixed point.

The mappings satisfying (1.1) are called Kannan-type mappings.

A similar type of contractive condition has been studied by Chatterjea [3]. He proved the following result.

Theorem 1.2 If $(X, d)$ is a complete metric space and $T: X \rightarrow X$ satisfies

$$
d(T x, T y) \leq k[d(x, T y)+d(y, T x)]
$$

where $0<k<\frac{1}{2}$ and $x, y \in X$, then $T$ has a unique fixed point. 
In Theorems 1.1 and 1.2, there is no the requirement for the continuity of $T$.

Alber and Guerre-Delabriere [4] introduced the concept of weakly contractive mappings and proved the existence of fixed points for single-valued weakly contractive mappings in Hilbert spaces. Thereafter, in 2001, Rhoades [5] proved the fixed point theorem which is one of the generalizations of Banach's contraction mapping principle because the weakly contractions contain contractions as a special case, and he also showed that some results of [4] are true for any Banach space. In fact, weakly contractive mappings are closely related to the mappings of Boyd and Wong [6] and of Reich types [7].

Fixed point problems involving different types of contractive type inequalities have been studied by many authors (see [1-24] and the references cited therein).

In [22], Kirk et al. introduced the following notion of a cyclic representation and characterized the Banach contraction principle in the context of a cyclic mapping.

Definition 1.1 [22] Let $X$ be a non-empty set and $T: X \rightarrow X$ be an operator. By definition, $X=\bigcup_{i=1}^{m} X_{i}$ is a cyclic representation of $X$ with respect to $T$ if

(a) $X_{i} ; i=1, \ldots, m$ are non-empty sets;

(b) $T\left(X_{1}\right) \subset X_{2}, \ldots, T\left(X_{m-1}\right) \subset X_{m}, T\left(X_{m}\right) \subset X_{1}$.

It is the aim of this paper to introduce the notion of a cyclic weakly Chatterjea-type contraction and then derive a fixed point theorem for such cyclic contractions in the framework of complete metric spaces.

\section{Main results}

To state and prove our main results, we will introduce our notion of a Chatterjea-type cyclic weakly contraction in a metric space. In this respect, let $\Phi$ denote the set of all monotone increasing continuous functions $\mu:[0, \infty) \rightarrow[0, \infty)$, with $\mu(t)=0$, if and only if $t=0$, and let $\Psi$ denote the set of all lower semi-continuous functions $\psi:[0, \infty)^{2} \rightarrow$ $[0, \infty)$, with $\psi\left(t_{1}, t_{2}\right)>0$, for $t_{1}, t_{2} \in(0, \infty)$ and $\psi(0,0)=0$.

Definition 2.1 Let $(X, d)$ be a metric space, $m$ be a natural number, $A_{1}, A_{2}, \ldots, A_{m}$ be nonempty subsets of $X$ and $Y=\bigcup_{i=1}^{m} A_{i}$. An operator $T: Y \rightarrow Y$ is called a Chatterjea-type cyclic weakly contraction if

(1) $\bigcup_{i=1}^{m} A_{i}$ is a cyclic representation of $Y$ with respect to $T$;

(2) $\mu(d(T x, T y)) \leq \mu\left(\frac{1}{2}[d(x, T y)+d(y, T x)]\right)-\psi(d(x, T y), d(y, T x))$

for any $x \in A_{i}, y \in A_{i+1}, i=1,2, \ldots, m$, where $A_{m+1}=A_{1}, \mu \in \Phi$ and $\psi \in \Psi$.

Theorem 2.1 Let $(X, d)$ be a complete metric space, $m \in \mathbb{N}, A_{1}, A_{2}, \ldots, A_{m}$ be non-empty closed subsets of $X$ and $Y=\bigcup_{i=1}^{m} A_{i}$. Suppose that $T$ is a Chatterjea-type cyclic weakly contraction. Then $T$ has a fixed point $z \in \bigcap_{i=1}^{n} A_{i}$.

Proof Let $x_{0} \in X$. We can construct a sequence $x_{n+1}=T x_{n}, n=0,1,2, \ldots$.

If there exists $n_{0} \in \mathbb{N}$ such that $x_{n_{0}+1}=x_{n_{0}}$, hence the result. Indeed, we can see that $T x_{n_{0}}=x_{n_{0}+1}=x_{n_{0}}$.

Now, we assume that $x_{n+1} \neq x_{n}$ for any $n=0,1,2, \ldots$ As $X=\bigcup_{i=1}^{m} A_{i}$, for any $n>0$, there exists $i_{n} \in\{1,2, \ldots, m\}$ such that $x_{n-1} \in A_{i_{n}}$ and $x_{n} \in A_{i_{n+1}}$. Since $T$ is a Chatterjea-type 
cyclic weakly contraction, we have

$$
\begin{aligned}
\mu\left(d\left(x_{n+1}, x_{n}\right)\right)= & \mu\left(d\left(T x_{n}, T x_{n-1}\right)\right) \\
\leq & \mu\left(\frac{1}{2}\left[d\left(x_{n}, T x_{n-1}\right)+d\left(x_{n-1}, T x_{n}\right)\right]\right) \\
& -\psi\left(d\left(x_{n}, T x_{n-1}\right), d\left(x_{n-1}, T x_{n}\right)\right) \\
= & \mu\left(\frac{1}{2} d\left(x_{n-1}, x_{n+1}\right)\right)-\psi\left(0, d\left(x_{n-1}, x_{n+1}\right)\right) \\
\leq & \mu\left(\frac{1}{2} d\left(x_{n-1}, x_{n+1}\right)\right) .
\end{aligned}
$$

Since $\mu$ is a non-decreasing function, for all $n=1,2, \ldots$, we have

$$
d\left(x_{n+1}, x_{n}\right) \leq \frac{1}{2} d\left(x_{n-1}, x_{n+1}\right) \leq \frac{1}{2}\left[d\left(x_{n-1}, x_{n}\right)+d\left(x_{n}, x_{n+1}\right)\right] .
$$

This implies that $d\left(x_{n+1}, x_{n}\right) \leq d\left(x_{n}, x_{n-1}\right)$. Thus $\left\{d\left(x_{n+1}, x_{n}\right)\right\}$ is a monotone decreasing sequence of non-negative real numbers and hence is convergent. Therefore, there exists $r \geq 0$ such that $d\left(x_{n+1}, x_{n}\right) \rightarrow r$. Letting $n \rightarrow \infty$ in (2.2), we obtain that $\lim d\left(x_{n-1}, x_{n+1}\right)=2 r$.

Letting $n \rightarrow \infty$ in (2.1) and using the continuity of $\mu$ and lower semi-continuity of $\psi$, we obtain that $\mu(r) \leq \mu(r)-\psi(0,2 r)$. This implies that $\psi(2 r, 0)=0$, hence $r=0$. Thus we have proved that

$$
d\left(x_{n+1}, x_{n}\right) \rightarrow 0 .
$$

Now, we show that $\left\{x_{n}\right\}$ is a Cauchy sequence. For this purpose, we prove the following result first.

Lemma 2.1 For every positive $\epsilon$, there exists a natural number $n$ such that if $r, q \geq n$ with $r-q \equiv 1(\bmod m)$, then $d\left(x_{r}, x_{q}\right)<\epsilon$.

Proof Assume the contrary. Thus there exists $\epsilon>0$ such that for any $n \in \mathbb{N}$, we can find $r_{n}>q_{n} \geq n$ with $r_{n}-q_{n} \equiv 1(\bmod m)$ satisfying $d\left(x_{r_{n}}, x_{q_{n}}\right) \geq \epsilon$.

Now, we take $n>2 m$. Then, corresponding to $q_{n} \geq n$, we can choose $r_{n}$ such that it is the smallest integer with $r_{n}>q_{n}$ satisfying $r_{n}-q_{n} \equiv 1(\bmod m)$ and $d\left(x_{r_{n}}, x_{q_{n}}\right) \geq \epsilon$. Therefore, $d\left(x_{r_{n-m}}, x_{q_{n}}\right)<\epsilon$. By using the triangular inequality, we have

$$
\begin{aligned}
\epsilon & \leq d\left(x_{q_{n}}, x_{r_{n}}\right) \\
& \leq d\left(x_{q_{n}}, x_{r_{n-m}}\right)+\sum_{i=1}^{m} d\left(x_{r_{n-i}}, x_{r_{n-i+1}}\right) \\
& <\epsilon+\sum_{i=1}^{m} d\left(x_{r_{n-i}}, x_{r_{n-i+1}}\right) .
\end{aligned}
$$

Letting $n \rightarrow \infty$ and using $d\left(x_{n+1}, x_{n}\right) \rightarrow 0$, we obtain

$$
\lim d\left(x_{q_{n}}, x_{r_{n}}\right)=\epsilon
$$


Again, by the triangular inequality,

$$
\begin{aligned}
\epsilon & \leq d\left(x_{q_{n}}, x_{r_{n}}\right) \\
& \leq d\left(x_{q_{n}}, x_{q_{n+1}}\right)+d\left(x_{q_{n+1}}, x_{r_{n+1}}\right)+d\left(x_{r_{n+1}}, x_{r_{n}}\right) \\
& \leq d\left(x_{q_{n}}, x_{q_{n+1}}\right)+d\left(x_{q_{n+1}}, x_{q_{n}}\right)+d\left(x_{q_{n}}, x_{r_{n}}\right)+d\left(x_{r_{n}}, x_{r_{n+1}}\right)+d\left(x_{r_{n+1}}, x_{r_{n}}\right) .
\end{aligned}
$$

Letting $n \rightarrow \infty$ and using $d\left(x_{n+1}, x_{n}\right) \rightarrow 0$, we get

$$
\lim d\left(x_{q_{n+1}}, x_{r_{n+1}}\right)=\epsilon
$$

Consider

$$
\begin{aligned}
d\left(x_{q_{n}}, T x_{r_{n}}\right) & =d\left(x_{q_{n}}, x_{r_{n+1}}\right) \\
& \leq d\left(x_{q_{n}}, x_{r_{n}}\right)+d\left(x_{r_{n}}, x_{r_{n+1}}\right),
\end{aligned}
$$

and

$$
\begin{aligned}
d\left(x_{r_{n}}, T x_{q_{n}}\right) & =d\left(x_{r_{n}}, x_{q_{n+1}}\right) \\
& \leq d\left(x_{r_{n}}, x_{q_{n}}\right)+d\left(x_{q_{n}}, x_{q_{n+1}}\right) .
\end{aligned}
$$

On taking $n \rightarrow \infty$ in inequalities (2.5) and (2.6), we have

$$
\lim _{n \rightarrow \infty} d\left(x_{q_{n}}, T x_{r_{n}}\right)=\epsilon,
$$

and

$$
\lim _{n \rightarrow \infty} d\left(x_{r_{n}}, T x_{q_{n}}\right)=\epsilon .
$$

As $x_{q_{n}}$ and $x_{r_{n}}$ lie in different adjacently labeled sets $A_{i}$ and $A_{i+1}$ for certain $1 \leq i \leq m$, using the fact that $T$ is a Chatterjea-type cyclic weakly contraction, we obtain

$$
\begin{aligned}
\mu(\epsilon) \leq & \mu\left(d\left(x_{q_{n+1}}, x_{r_{n+1}}\right)\right) \\
= & \mu\left(d\left(T x_{q_{n}}, T x_{r_{n}}\right)\right) \\
\leq & \mu\left(\frac{1}{2}\left[d\left(x_{q_{n}}, T x_{r_{n}}\right)+d\left(x_{r_{n}}, T x_{q_{n}}\right)\right]\right) \\
& -\psi\left(d\left(x_{q_{n}}, T x_{r_{n}}\right), d\left(x_{r_{n}}, T x_{q_{n}}\right)\right) \\
= & \mu\left(\frac{1}{2}\left[d\left(x_{q_{n}}, x_{r_{n+1}}\right)+d\left(x_{r_{n}}, x_{q_{n+1}}\right)\right]\right) \\
& -\psi\left(d\left(x_{q_{n}}, x_{r_{n+1}}\right), d\left(x_{r_{n}}, x_{q_{n+1}}\right)\right) .
\end{aligned}
$$

On taking $n \rightarrow \infty$ in (2.9), using (2.7) and (2.8), the continuity of $\mu$ and lower semicontinuity of $\psi$, we get that

$$
\mu(\varepsilon) \leq \mu\left(\frac{1}{2}[\varepsilon+\varepsilon]\right)-\psi(\varepsilon, \varepsilon) .
$$


Consequently, $\psi(\varepsilon, \varepsilon) \leq 0$, which is contradiction with $\varepsilon>0$. Hence the result is proved.

Now, using Lemma 2.1, we will show that $\left\{x_{n}\right\}$ is a Cauchy sequence in $Y$. Fix $\epsilon>0$. By Lemma 2.1, we can find $n_{0} \in \mathbb{N}$ such that $r, q \geq n_{0}$ with $r-q \equiv 1(\bmod m)$

$$
d\left(x_{r}, x_{q}\right) \leq \frac{\epsilon}{2}
$$

Since $\lim d\left(x_{n}, x_{n+1}\right)=0$, we can also find $n_{1} \in \mathbb{N}$ such that

$$
d\left(x_{n}, x_{n+1}\right) \leq \frac{\epsilon}{2 m}
$$

for any $n \geq n_{1}$.

Assume that $r, s \geq \max \left\{n_{0}, n_{1}\right\}$ and $s>r$. Then there exists $k \in\{1,2, \ldots, m\}$ such that $s-r \equiv k(\bmod m)$. Hence $s-r+t=1(\bmod m)$ for $t=m-k+1$. So, we have

$$
d\left(x_{r}, x_{s}\right) \leq d\left(x_{r}, x_{s+j}\right)+d\left(x_{s+j}, x_{s+j-1}\right)+\cdots+d\left(x_{s+1}, x_{s}\right) .
$$

Using (2.10), (2.11) and (2.12), we obtain

$$
d\left(x_{r}, x_{s}\right) \leq \frac{\epsilon}{2}+j \times \frac{\epsilon}{2 m} \leq \frac{\epsilon}{2}+m \times \frac{\epsilon}{2 m}=\epsilon .
$$

Hence $\left\{x_{n}\right\}$ is a Cauchy sequence in $Y$. Since $Y$ is closed in $X$, then $Y$ is also complete and there exists $x \in Y$ such that $\lim x_{n}=x$.

Now, we will prove that $x$ is a fixed point of $T$.

As $Y=\bigcup_{i=1}^{m} A_{i}$ is a cyclic representation of $Y$ with respect to $T$, the sequence $\left\{x_{n}\right\}$ has infinite terms in each $A_{i}$ for $i=\{1,2, \ldots, m\}$. Suppose that $x \in A_{i}, T x \in A_{i+1}$ and we take a subsequence $\left\{x_{n_{k}}\right\}$ of $\left\{x_{n}\right\}$ with $x_{n_{k}} \in A_{i}$. By using the contractive condition, we can obtain

$$
\begin{aligned}
\mu\left(d\left(x_{n_{k}+1}, T x\right)\right)= & \mu\left(d\left(T x_{n_{k}}, T x\right)\right) \\
\leq & \mu\left(\frac{1}{2}\left[d\left(x_{n_{k}}, T x\right)+d\left(x, T x_{n_{k}}\right)\right]\right) \\
& -\psi\left(d\left(x_{n_{k}}, T x\right), d\left(x, T x_{n_{k}}\right)\right) \\
= & \mu\left(\frac{1}{2}\left[d\left(x_{n_{k}}, T x\right)+d\left(x, x_{n_{k}+1}\right)\right]\right) \\
& -\psi\left(d\left(x_{n_{k}}, T x\right), d\left(x, x_{n_{k}+1}\right)\right) .
\end{aligned}
$$

Letting $n \rightarrow \infty$ and using the continuity of $\mu$ and lower semi-continuity of $\psi$, we have

$$
\mu(d(x, T x)) \leq \mu\left(\frac{1}{2} d(x, T x)\right)-\psi(d(x, T x), 0)
$$

which is a contradiction unless $d(x, T x)=0$. Hence $x$ is a fixed point of $T$.

Now, we will prove the uniqueness of the fixed point. 
Suppose that $x_{1}$ and $x_{2}\left(x_{1} \neq x_{2}\right)$ are two fixed points of $T$. Using the contractive condition and the continuity of $\mu$ and lower semi continuity of $\psi$, we have

$$
\begin{aligned}
\mu\left(d\left(x_{1}, x_{2}\right)\right) & =\mu\left(d\left(T x_{1}, T x_{2}\right)\right) \\
& \leq \mu\left(\frac{1}{2}\left[d\left(x_{1}, T x_{2}\right)+d\left(x_{2}, T x_{1}\right)\right]\right)-\psi\left(d\left(x_{1}, T x_{2}\right), d\left(x_{2}, T x_{1}\right)\right) \\
& =\mu\left(\frac{1}{2}\left[d\left(x_{1}, x_{2}\right)+d\left(x_{2}, x_{1}\right)\right]\right)-\psi\left(d\left(x_{1}, x_{2}\right), d\left(x_{2}, x_{1}\right)\right) \\
& =\mu\left(d\left(x_{1}, x_{2}\right)\right)-\psi\left(d\left(x_{1}, x_{2}\right), d\left(x_{2}, x_{1}\right)\right) \\
& \leq \mu\left(d\left(x_{1}, x_{2}\right)\right),
\end{aligned}
$$

which is a contradiction unless $x_{1}=x_{2}$. Hence the main result is proved.

If $\mu(a)=a$, then we have the following result.

Corrollary 2.1 Let $(X, d)$ be a complete metric space, $m \in \mathbb{N}, A_{1}, A_{2}, \ldots, A_{m}$ be non-empty closed subsets of $X$ and $Y=\bigcup_{i=1}^{m} A_{i}$. Suppose that $T: Y \rightarrow Y$ is an operator such that

(1) $\bigcup_{i=1}^{m} A_{i}$ is a cyclic representation of $Y$ with respect to $T$;

(2) $d(T x, T y) \leq \frac{1}{2}[d(x, T y)+d(y, T x)]-\psi(d(x, T y), d(y, T x))$

for any $x \in A_{i}, y \in A_{i+1}, i=1,2, \ldots, m$, where $A_{m+1}=A_{1}$ and $\psi \in \Psi$. Then $T$ has a fixed point $z \in \bigcap_{i=1}^{n} A_{i}$.

If $\psi(a, b)=\left(\frac{1}{2}-k\right)(a+b)$, where $k \in\left[0, \frac{1}{2}\right)$, we have the following result.

Corrollary 2.2 Let $(X, d)$ be a complete metric space, $m \in \mathbb{N}, A_{1}, A_{2}, \ldots, A_{m}$ be non-empty closed subsets of $X$ and $Y=\bigcup_{i=1}^{m} A_{i}$. Suppose that $T: Y \rightarrow Y$ is an operator such that

(1) $\bigcup_{i=1}^{m} A_{i}$ is a cyclic representation of $Y$ with respect to $T$;

(2) there exists $k \in\left[0, \frac{1}{2}\right)$ such that $d(T x, T y) \leq k[d(x, T y)+d(y, T x)]$

for any $x \in A_{i}, y \in A_{i+1}, i=1,2, \ldots, m$, where $A_{m+1}=A_{1}$. Then $T$ has a fixed point $z \in \bigcap_{i=1}^{n} A_{i}$.

\section{Applications}

Other consequences of our results, for mappings involving contractions of integral type, are given in the following. In this respect, denote by $\Lambda$ the set of functions $\mu:[0, \infty) \rightarrow$ $[0, \infty)$ satisfying the following hypotheses:

(h1) $\mu$ is a Lebesgue-integrable mapping on each compact of $[0, \infty)$;

(h2) for any $\epsilon>0$, we have $\int_{0}^{\epsilon} \mu(t)>0$.

Corrollary 3.1 Let $(X, d)$ be a complete metric space, $m \in \mathbb{N}, A_{1}, A_{2}, \ldots, A_{m}$ be non-empty closed subsets of $X$ and $Y=\bigcup_{i=1}^{m} A_{i}$. Suppose that $T: Y \rightarrow Y$ is an operator such that

(1) $\bigcup_{i=1}^{m} A_{i}$ is a cyclic representation of $Y$ with respect to $T$;

(2) there exists $k \in\left[0, \frac{1}{2}\right)$ such that

$$
\int_{0}^{d(T x, T y)} \alpha(s) d s \leq k \int_{0}^{d(x, T y)+d(y, T x)} \alpha(s) d s
$$

for any $x \in A_{i}, y \in A_{i+1}, i=1,2, \ldots, m$, where $A_{m+1}=A_{1}$ and $\alpha \in \Lambda$. Then $T$ has a fixed point $z \in \bigcap_{i=1}^{n} A_{i}$. 
If we take $A_{i}=X, i=1,2, \ldots, m$, we obtain the following result.

Corrollary 3.2 Let $(X, d)$ be a complete metric space and $T: X \rightarrow X$ be a mapping such that

$$
\int_{0}^{d(T x, T y)} \alpha(s) d s \leq k \int_{0}^{d(x, T y)+d(y, T x)} \alpha(s) d s,
$$

for any $x y \in X, k \in\left[0, \frac{1}{2}\right)$ and $\alpha \in \Lambda$. Then $T$ has a fixed point $z \in \bigcap_{i=1}^{n} A_{i}$.

Example 3.1 Let $X$ be a subset in $\mathbb{R}$ endowed with the usual metric. Suppose $A_{1}=[0,1]$, $A_{2}=\left[0, \frac{1}{2}\right]$ and $Y=\bigcup_{i=1}^{2} A_{i}$. Define $T: Y \rightarrow Y$ such that $T x=\frac{x}{5}$ for all $x \in Y$. It is clear that $\bigcup_{i=1}^{2} A_{i}$ is a cyclic representation of $Y$ with respect to $T$. Furthermore, if $\mu:[0, \infty) \rightarrow$ $[0, \infty)$ is given as $\mu(t)=t$ and $\psi:[0, \infty)^{2} \rightarrow[0, \infty)$ is given by $\psi(x, y)=\frac{1}{7}(x+y)$, then $\psi \in \Psi$.

Now, we prove that $T$ satisfies the inequality of Chatterjea-type cyclic weakly contraction, i.e., $\mu(d(T x, T y)) \leq \mu\left(\frac{1}{2}[d(x, T y)+d(y, T x)]\right)-\psi(d(x, T y), d(y, T x))$. To see this fact, we examine three cases.

Case 1 . Suppose that $x \geq y$. Then

$$
\mu(d(T x, T y))=\mu\left(\left|\frac{x}{5}-\frac{y}{5}\right|\right)=\frac{x-y}{5}
$$

and

$$
\begin{aligned}
\mu( & \left.\frac{1}{2}[d(x, T y)+d(y, T x)]\right)-\psi(d(x, T y), d(y, T x)) \\
& =\mu\left(\frac{1}{2}\left[\left|x-\frac{y}{5}\right|+\left|y-\frac{x}{5}\right|\right]\right)-\psi\left(\left|x-\frac{y}{5}\right|,\left|y-\frac{x}{5}\right|\right) \\
& =\frac{1}{2}\left[\left|x-\frac{y}{5}\right|+\left|y-\frac{x}{5}\right|\right]-\frac{1}{7}\left[\left|x-\frac{y}{5}\right|+\left|y-\frac{x}{5}\right|\right] \\
& =\frac{5}{14}\left[\left|x-\frac{y}{5}\right|+\left|y-\frac{x}{5}\right|\right] .
\end{aligned}
$$

If $y<\frac{x}{5}$, then

$$
\begin{aligned}
\frac{x-y}{5} & \leq \frac{5}{14}\left[x-\frac{y}{5}+\frac{x}{5}-y\right] \\
& =\frac{3}{7}(x-y) .
\end{aligned}
$$

Hence, the given inequality is satisfied.

If $y \geq \frac{x}{5}$, then

$$
\begin{aligned}
\frac{x-y}{5} & \leq \frac{5}{14}\left[x-\frac{y}{5}+y-\frac{x}{5}\right] \\
& =\frac{2}{7}(x+y) .
\end{aligned}
$$

Hence the given inequality is satisfied. 
Case 2. Suppose that $\frac{y}{5} \leq x \leq y$. Then from (3.1) and (3.2), we have

$$
\begin{aligned}
\frac{x-y}{5} & \leq \frac{5}{14}\left[x-\frac{y}{5}+y-\frac{x}{5}\right] \\
& =\frac{2}{7}(x+y) .
\end{aligned}
$$

Hence the given inequality is satisfied.

Case 3. Finally, suppose that $\frac{y}{5} \geq x$. Then from (3.1) and (3.2), we have

$$
\mu(d(T x, T y))=\mu\left(\left|\frac{x}{5}-\frac{y}{5}\right|\right)=\frac{y-x}{5}
$$

and

$$
\begin{aligned}
\frac{x-y}{5} & \leq \frac{5}{14}\left[x-\frac{y}{5}+y-\frac{x}{5}\right] \\
& =\frac{2}{7}(x+y) .
\end{aligned}
$$

Hence the given inequality is satisfied.

Therefore, all the conditions of Theorem 2.1 are satisfied, and so $T$ has a fixed point (which is $z=0 \in \bigcap_{i=1}^{2} A_{i}$ ).

\section{Competing interests}

The authors declare that they have no competing interests.

\section{Authors' contributions}

Both authors contributed equally and significantly in writing this article. Both authors read and approved the final manuscript.

\section{Author details}

'Department of Mathematics, Khalsa College of Engineering \& Technology (Punjab Technical University), Ranjit Avenue, Amritsar, 143001, India. ²Faculty of Applied Sciences, University Politehnica of Bucharest, 313 Splaiul Independenţei, Bucharest, 060042, Romania.

\section{Acknowledgements}

The authors are thankful to learned referee(s) for suggestions.

Received: 28 November 2012 Accepted: 27 January 2013 Published: 11 February 2013

\section{References}

1. Kannan, R: Some results on fixed points. Bull. Calcutta Math. Soc. 60, 71-76 (1968)

2. Kannan, R: Some results on fixed points-II. Am. Math. Mon. 76, 405-408 (1969)

3. Chatterjea, SK: Fixed point theorem. C. R. Acad. Bulgare Sci. 25, 727-730 (1972)

4. Alber, Y, Guerre-Delabriere, S: Principles of Weakly Contractive Maps in Hilbert Spaces. In: Gohberg, I, Lyubich, Y (eds.) New Results in Operator Theory and Its Applications. Oper. Theory Adv. Appl., vol. 8, pp. 7-22. Birkhäuser, Basel (1997)

5. Rhoades, BE: Some theorems on weakly contractive maps. Nonlinear Anal. 47, 2683-2693 (2001)

6. Boyd, DW, Wong, TSW: On nonlinear contractions. Proc. Am. Math. Soc. 20, 458-464 (1969)

7. Reich, S: Some fixed point problems. Atti Accad. Naz. Lincei, Rend. Cl. Sci. Fis. Mat. Nat. 57, 194-198 (1975)

8. Aydi, H, Karapınar, E, Postolache, M: Tripled coincidence point theorems for weak $\varphi$-contractions in partially ordered metric spaces. Fixed Point Theory Appl. 2012, Article ID 44 (2012)

9. Aydi, H, Shatanawi, W, Postolache, M, Mustafa, Z, Tahat, N: Theorems for Boyd-Wong type contractions in ordered metric spaces. Abstr. Appl. Anal. 2012, Article ID 359054 (2012)

10. Chandok, S: Some common fixed point theorems for generalized $f$-weakly contractive mappings. J. Appl. Math Inform. 29, 257-265 (2011)

11. Chandok, S: Some common fixed point theorems for generalized nonlinear contractive mappings. Comput. Math. Appl. 62, 3692-3699 (2011)

12. Chandok, S: Common fixed points, invariant approximation and generalized weak contractions. Int. J. Math. Math. Sci. 2012, Article ID 102980 (2012) 
13. Chandok, S, Kim, JK: Fixed point theorem in ordered metric spaces for generalized contractions mappings satisfying rational type expressions. J. Nonlinear Funct. Anal. Appl. 17, 301-306 (2012)

14. Chandok, S: Common fixed points for generalized nonlinear contractive mappings in metric spaces. Mat. Vesn. 65 , 29-34 (2013)

15. Chandok, S: A fixed point result for weakly Kannan type cyclic contractions. Int. J. Pure Appl. Math. 82(2), 253-260 (2013)

16. Chandok, S: Some common fixed point results for generalized weak contractive mappings in partially ordered metric spaces. J. Nonlinear Anal. Optim. (2013, in press)

17. Chandok, S, Karapinar, E: Some common fixed point results for generalized rational type weak contraction mappings in partially ordered metric spaces. Thai J. Math. (2013, in press)

18. Chandok, S, Khan, MS, Rao, KPR: Some coupled common fixed point theorems for a pair of mappings satisfying a contractive condition of rational type without monotonicity. Int. J. Math. Anal. 7(9), 433-440 (2013)

19. Haghi, RH, Postolache, M, Rezapour, S: On T-stability of the Picard iteration for generalized $\varphi$-contraction mappings. Abstr. Appl. Anal. 2012, Article ID 658971 (2012)

20. Karapinar, E, Sadarangani, K: Fixed point theory for cyclic $(\phi-\psi)$-contractions. Fixed Point Theory Appl. 2011, Article ID 69 (2011)

21. Karapinar, E, Erhan, IM: Best proximity on different type contractions. Appl. Math. Inf. Sci. 5, 342-353 (2011)

22. Kirk, WA, Srinivasan, PS, Veeramani, P: Fixed points for mappings satisfying cyclical contractive conditions. Fixed Point Theory Appl. 4(1), 79-89 (2003)

23. Olatinwo, MO, Postolache, M: Stability results for Jungck-type iterative processes in convex metric spaces. Appl. Math. Comput. 218(12), 6727-6732 (2012)

24. Zhou, $\mathrm{X}, \mathrm{Wu}, \mathrm{W}, \mathrm{Ma}, \mathrm{H}$ : A contraction fixed point theorem in partially ordered metric spaces and application to fractional differential equations. Abstr. Appl. Anal. 2012, Article ID 856302 (2012)

doi:10.1186/1687-1812-2013-28

Cite this article as: Chandok and Postolache: Fixed point theorem for weakly Chatterjea-type cyclic contractions. Fixed Point Theory and Applications 2013 2013:28

\section{Submit your manuscript to a SpringerOpen ${ }^{\circ}$ journal and benefit from:}

- Convenient online submission

- Rigorous peer review

- Immediate publication on acceptance

Open access: articles freely available online

- High visibility within the field

- Retaining the copyright to your article 